\title{
A CROSS-SECTIONAL STUDY ON THE PREVALENCE OF DISTAL SENSORY NEUROPATHY IN ASYMPTOMATIC TYPE 2 DIABETES PATIENTS IN A TERTIARY CARE CENTRE
}

\author{
D. Anbarasu', S. P. Kumaresan², N. Vijayakumar³, S. Thirunavukkarasu4
}

${ }^{1}$ Associate Professor, Department of Medicine, Government Vellore Medical College.

${ }^{2}$ Associate Professor, Department of Medicine, Government Vellore Medical College.

${ }^{3}$ Postgraduate, Department of General Medicine, Government Vellore Medical College.

${ }^{4}$ Postgraduate, Department of General Medicine, Government Vellore Medical College.

\begin{tabular}{l}
\hline ABSTRACT \\
OBJECTIVE \\
To determine the prevalence of Distal Sensory neuropathy in asymptomatic Type 2 Diabetes mellitus. \\
METHODOLOGY \\
Patients with type 2 diabetes mellitus attending outpatient Department of Government Vellore Medical College Hospital without \\
symptoms of peripheral neuropathy were included in this study. The presence of diabetic neuropathy was diagnosed using Michigan \\
Neuropathy Screening Instrument (MNSI) Score.
\end{tabular}

RESULTS

A total of 400 patients with type 2 diabetes mellitus were studied of which 216 (54\%) were males and 184 (46\%) were females. Mean age of males was significantly higher than females $(51 \pm 9.1$ years vs. $44 \pm 7.6$ years, $\mathrm{p}<0.05)$. The mean BMI of females was significantly higher for females than males $(28.4 \pm 4.2$ vs. $25.3 \pm 2.9, \mathrm{p}<0.05)$. In our study, 72 patients $(18 \%)$ had asymptomatic peripheral neuropathy.

\section{CONCLUSION}

Peripheral neuropathy is common in asymptomatic diabetic patients. All patients with diabetes mellitus needs active screening for peripheral neuropathy to reduce the morbidity associated with it.

\section{KEYWORDS}

MNSI Scoring, Semmes-Weinstein Monofilament, Neuropathy, Diabetes Mellitus.

HOW TO CITE THIS ARTICLE: Anbarasu D, Kumaresan SP, Vijayakumar N, et al. A cross-sectional study on the prevalence of distal sensory neuropathy in asymptomatic type 2 diabetes patients in a tertiary care centre. J. Evolution Med. Dent. Sci. 2016;5(73): 5352-5354, DOI: $10.14260 /$ jemds/2016/1214

\section{INTRODUCTION}

Diabetes Mellitus has become a global epidemic. There are currently an estimated number of more than 69.1 million people suffering from this disease in India. ${ }^{1}$ By the year 2030, it is estimated that there will be nearly 80 million Indians with Diabetes. It is associated with more than two fold excess mortality from cardiovascular disease, devastating microvascular complication affecting the eyes, kidney and nerves as well as comorbidity including cancer, infection and psychosocial stress.

Diabetic Peripheral Neuropathy (DPN) is one of the commonest symptomatic complications of Diabetes. 2,3 Prevalence of Diabetic peripheral Neuropathy is 15 to 50 percent in various studies. ${ }^{4,5}$ It predisposes to foot ulceration and gangrene. Type 2 Diabetes Mellitus is characterised by long asymptomatic phase (ranges from 4 to 7 years) between the actual onset of hyperglycaemia and clinical diagnosis, which may explain the relatively high prevalence of microvascular complication in newly-diagnosed patients with

Financial or Other, Competing Interest: None.

Submission 19-08-2016, Peer Review 01-09-2016,

Acceptance 03-09-2016, Published 10-09-2016.

Corresponding Author:

Dr. D. Anbarasu,

No. 34/E, Vellore Main Road,

Arcot, Vellore-632503,

Tamilnadu.

E-mail: dr.anbarasu.md@gmail.com

DOI: $10.14260 /$ jemds/2016/1214
Type 2 Diabetes Mellitus. In view of poor awareness and lack of regular screening programmes, the initial presentation to the physicians is delayed frequently. This may predispose to increased rate of microvascular complication at onset.

There is an emerging evidence that Peripheral Neuropathy begins in the early stages of Diabetes pathogenesis and remains asymptomatic during the course of the disease. Early detection of peripheral neuropathy and appropriate management of the same would reduce the complication of foot ulcers. ${ }^{6,7}$ As per previous studies on diabetes mellitus, $3 \%$ of patients presented with overt neuropathy, $10 \%$ presented with borderline neuropathy at the time of diagnosis of diabetes mellitus and another $10 \%$ of patients subsequently developed neuropathy.8,9 Hence, this study aims at screening peripheral neuropathy and determine the prevalence of the disease in asymptomatic diabetic population.

\section{METHODOLOGY}

This cross-sectional study was done on patients attending the diabetic clinic and medical OPD at Govt. Vellore Medical College Hospital from March 2016 to August 2016. Known patients of type 2 diabetes mellitus without any symptom of peripheral neuropathy at the time of examination were included after obtaining informed consent. Patients with type 1 diabetes mellitus, vitamin B12 deficiency, hypothyroidism, uraemia, HIV disease, malignancy, tuberculosis, chronic alcoholism, pregnancy, Hansen's disease and those taking drugs that cause peripheral neuropathy were excluded from the study. Patient's age, gender, history of smoking and 
alcoholism, height, weight, BMI and blood pressure were recorded. A detailed clinical examination was performed. Blood samples were taken for fasting and postprandial blood glucose, HbA1C levels and lipid profile. Diagnosis of diabetes mellitus made as per the ADA criteria. All patients were examined for appearance of feet, presence of ulcerations, vibration perception, ankle reflexes and monofilament. Based on the above-mentioned parameters, MNSI scoring was done. A diagnosis of peripheral neuropathy was made when the MNSI scoring $\geq 2$ out of 10 .

\section{RESULTS}

A total sample of 400 patients were studied. Of this, 216 (54\%) were males and 184 (46\%) were females. Mean age of males was $51 \pm 9.1$ years and that of females was $44 \pm 7.6$ years. The mean age of females was significantly lesser than the mean age of males ( $p<0.05)$. The mean BMI of males was $25.3 \pm 2.9$ and that of females was $28.4 \pm 4.2$. The mean systolic blood pressure of males was $136.6 \pm 15.2 \mathrm{mmHg}$ and that of females was $127.4 \pm 13.1 \mathrm{mmHg}$. The mean diastolic blood pressure of males was $83 \pm 10.4 \mathrm{mmHg}$ and that of females was $82 \pm 9.8$ mmHg. The mean systolic blood pressure is significantly higher in males than females ( $p<0.05$ ). Of the total sample of 400 subjects, 166 patients (41.5\%) had systemic hypertension. Among those with hypertension, 96 patients (57.8\%) were males and 70 patients $(42.1 \%)$ were females and this difference is statistically significant ( $p<0.05) .72$ patients (18\%) had a MNSI score of more than 2 suggesting the presence of peripheral neuropathy. Of these 72 patients with peripheral neuropathy, 38 (52.7\%) were males and 34 $(47.22 \%)$ were females $(p>0.05)$.

\begin{tabular}{|c|c|c|c|}
\hline Variables & Males & Females & $\begin{array}{c}\text { P } \\
\text { Value }\end{array}$ \\
\hline Mean Age in Years & $51 \pm 9.1$ & $44 \pm 7.6$ & $<0.05$ \\
\hline BMI & $25.3 \pm 2.9$ & $28.4 \pm 4.2$ & $<0.05$ \\
\hline $\begin{array}{c}\text { Systolic BP } \\
\text { (mmHg) }\end{array}$ & $136.6 \pm 15.2$ & $127.4 \pm 13.1$ & $<0.05$ \\
\hline $\begin{array}{c}\text { Diastolic BP } \\
\text { (mmHg) }\end{array}$ & $83 \pm 10.4$ & $82 \pm 9.8$ & $>0.05$ \\
\hline MNSI Score >2 & $52.7 \%$ & $47.2 \%$ & $>0.05$ \\
\hline \multicolumn{3}{|c|}{ Table 1: Demographic Data } \\
\hline
\end{tabular}

\section{DISCUSSION}

Our study which was done in a tertiary care hospital showed that the prevalence of diabetic peripheral neuropathy among asymptomatic patients is $18 \%$. There was no statistically significant difference in the prevalence of asymptomatic peripheral neuropathy between males and females. Thus, both genders are equally susceptible to diabetic peripheral neuropathy. The prevalence of asymptomatic peripheral neuropathy was $14.4 \%$ in the study done by Rehan Ahmed et $\mathrm{al}^{10}$ where the diagnosis of neuropathy was made using only the SW monofilament examination. In our study, the diagnosis of peripheral neuropathy was done using MNSI ${ }^{11}$ scoring system, which is a better predictor than monofilament examination alone. ${ }^{12}$ The mean BMI of the females is significantly higher than the mean BMI of males. The prevalence of systemic hypertension is significantly higher in males than females. Autonomic neuropathy, cranial neuropathy and multifocal motor neuropathy have been documented to present asymptomatically. ${ }^{33,14,15}$
The incidence of diabetic foot is higher in patients with poor glycaemic control. Early detection of peripheral neuropathy and appropriate management of the same will reduce the incidence of amputations due to diabetic foot.

\section{CONCLUSION}

Peripheral neuropathy, which is one of the microvascular complications of diabetes mellitus can present even without symptoms. Active screening of peripheral neuropathy in all patients with diabetes mellitus is needed to reduce the morbidity associated with it.

\section{REFERENCES}

1. International Diabetes Federation 2015. http://www.idf.org/membership/sea/india.

2. Rogers LC, Bevilacqua NJ, Malik RA, et al. Neuropathy in diabetes: not a knee-jerk diagnosis. J Am Podiatr Med Assoc 2008;98(4):322-5.

3. Agarwal RP, Sharma P, Pal M, et al. Magnitude of dyslipidemia and its association with micro and macrovascular complications in type 2 diabetes: a hospital based study from Bikaner, Northwest India. Diabetes Res Clin Pract 2006;73(2):211-4.

4. Canavan RJ, Unwin NC, Kelly WF, et al. Diabetes and nondiabetes related lower extremity amputation incidence before and after the introduction of better organised diabetes foot care: continuous longitudinal monitoring using a standard method. Diabetes Care 2008;31(3): 459-63.

5. Mojaddidi MA, Aboonq M, Nozha OM, et al. Early diagnosis of diabetic neuropathy in almadinnah almunawarrah. Jounal of Taibah Univ Med Sci 2011;6(2):121-31.

6. Lee S, Kim H, Choi S, et al. Clinical usefulness of the twosite semmes-weinstein monofilament test for detecting diabetic peripheral neuropathy. J Korean Med Sci 2003;18(1):103-7.

7. Olaleye D, Perkins BA, Bril V. Evaluation of three screening tests and a risk assesment model for diagnosing peripheral neuropathy in the diabetes clinic. Diab Res Clin Pract 2001;54(2):115-28.

8. Palumbo PJ, Elveback LR, Whisnant JP. Neurologic complications of diabetes mellitus: transient ischemic attack, stroke, and peripheral neuropathy. Adv Neurol 1978;19:593-601.

9. Rota E, Quadri R, Fanti E, et al. Clinical and electrophysiological correlations in type 2 diabetes mellitus at diagnosis. Diabetes Res Clin Pract 2007;76(1):152-4.

10. Ahmed SR, Zuberi BF, Afsar S. Frequency of sensory neuropathy in asymptomatic type 2 diabetic patients using semmes-weinstein monofilament. Pak J Med Sci 2009;25(3 part II):349-52.

11. Herman $\mathrm{WH}, \mathrm{Bu}$-sui $\mathrm{PR}, \mathrm{Braffett} \mathrm{BH}$, et al. Use of the Michigan neuropathy screening instrument as a measure of distal symmetrical peripheral neuropathy in type 1 diabetes: results from the diabetes control and complications trial/epidemiology of diabetes interventions and complications diabetes. Diabet Med 2012;29(7):937-44.

12. Jia WP, Shen $Q, B a o Y Q$, et al. Evaluation of four simple methods in the diagnosis of diabetic peripheral neuropathy. Zhonghua Yi Xue Za Zhi 2006;86(38): 2707-10. 
13. Uzun N, Ulunduz D, Mikla S. Evaluation of asymptomatic cranial neuropathy in type $1 \mathrm{DM}$. Electromyography Clin Neurophysio 2006;46:131-7.

14. Reisin RC, Zurru C, Buso C, et al. Multifocal motor neuropathy, type 1 diabetes and asymptomatic haschimoto's thyroiditis: an unusual association. Neuromuscul Disord 2005;15(5):358-60.
15. Rutter MK, McComb JM, Brady S, et al. Autonomic neuropathy in asymptomatic subjects with non-insulin dependent diabetes mellitus and microalbuminuria. Clin Auton Res 1998;8(5):251-7. 